\title{
The Effect of Double Racial Minority Status on Economic Performance in the United States
}

\author{
Sung David Chun ${ }^{1}$ \\ ${ }^{1}$ Professor, Mercy College of Ohio, Toledo, Ohio, USA \\ Correspondence: Sung David Chun, Professor of Sociology, Mercy College of Ohio, 2221 Madison Ave, Toledo, \\ OH 43604, USA. Tel: 419-251-1791.
}

Received: May 12, 2016

Accepted: June 1, 2016

Online Published: June 21, 2016

doi:10.5430/rwe.v7n1p95

URL: http://dx.doi.org/10.5430/rwe.v7n1p95

\begin{abstract}
Using 2010 SF3, 2010 SF3 5 \% PUMS, and 2011-2013 American Community Survey PUMS datasets, this study tackles the controversial subject of race within the multinational and multiracial Latino context. How do race, nationality, and nativity influence the economic characteristics of Latinos? Results of our study based on 2010 SF3 and 2010 SF3 $5 \%$ PUMS demonstrate that white Latinos are more successful than black Latinos, apparently by virtue of their non-black status, in terms of general economic measures. In addition, black Latinos have more in common with non-Latino blacks than with Latinos overall and white Latinos. Our further analyses find that black and white disparities vary among Latino origin groups. In terms of poverty rate and median household income, black Latinos have significantly disadvantaged profiles compared to their white counterparts virtually within every Latino national group.
\end{abstract}

Keywords: minorities, Hispanics, African Americans, economic performance

\section{Introduction: The Unacknowledged Black Latinos}

Black Latinos (Note 1) do not represent a significant share of our total population but they are disproportionately poor and underemployed. Yet black Latinos and the unique challenges they face are often overlooked by scholars and policymakers. Black Latinos face significant educational, social, and economic challenges, just as their white counterparts do, but many of these problems are exacerbated by their skin colors (Gómez 2000). Black Latinos are also struggling to establish their identity in a society which demands that they choose between their race and their nationality.

\section{Research Questions}

This paper explores the economic well-being of the 0.71 million Latinos who reported their race as black in 2010 and then examines the 2010 demographic profile and social background of black Latinos, which would have some effect on their low economic performance. The comparisons consider Latinos and non-Latinos as a whole and disaggregated by whites and blacks, that is, by white Latinos, black Latinos, non-Latino whites, and non-Latino blacks. (Note 2) We hope that this paper will revise many outdated yet still popular images of Latino life. Because understanding of the nation's Latinos is primarily informed by national Latino data as a whole, their descriptions can be heavily influenced by the whole 37 million Latinos regardless of historical differences and variations in each national-origin group (Oboler 1995; Zavella 1997). This paper provides a fresh perspective by offering a comprehensive and diverse profile of black Latinos through widely accepted demographic, socio and economic indicators.

\section{Data and Measures}

We retrieved cross tabulations from the 2010 Decennial Census long form and short form data, using the Advanced Query System from which the general public is not allowed to download data. The Advanced Query System enables us to tabulate many social and economic profiles of race and Latino origin, which do not exist in the pretabulated summary files from the 2010 Census SF1 and SF3. Our tables are more accurate than previous analyses using Public Use Micro data Samples or PUMS, such as the widely touted John R. Logan's (2003) report, simply because PUMS are 1 percent or 5 percent micro data samples of the 2010 Census data. In addition, our aggregated tables are reliable even at the local level while PUMS are at best reliable at the national level. 


\section{Black Latinos in the 2010 Census: Diversity within the Latino Population}

The 2010 Census considers race and Latino origin to be two separate and distinct concepts. These separate questions enable us to investigate Latino and non-Latino variation of racial self-identification. Since Latinos surpassed African-Americans as the country's largest minority in 2003 (Note 3), Latinos who are also black have been increasingly asserting their place as a Latino subgroup. However, only 2.0 percent of Latinos counted in the 2010 Census identified themselves as black. According to Figure 1, 47.9 percent of Latinos reported "white alone" even though many Americans might not see some of them that way. Another 42.2 percent of those identifying themselves as "Hispanic," "Spanish" or "Latino" also identified themselves as a member of "some other race" besides black or white. According to Logan (2003), Latinos are increasingly choosing to not identify themselves as either black or white. In the 2000 Census, only 33.7 percent of Latinos chose to forgo any racial classification while in 2010, 47.4 percent did not choose a race. The 2010 Census allowed more than one racial category to be selected for the first time. Thus, an additional 6.3 percent said they were members of "two or more races."

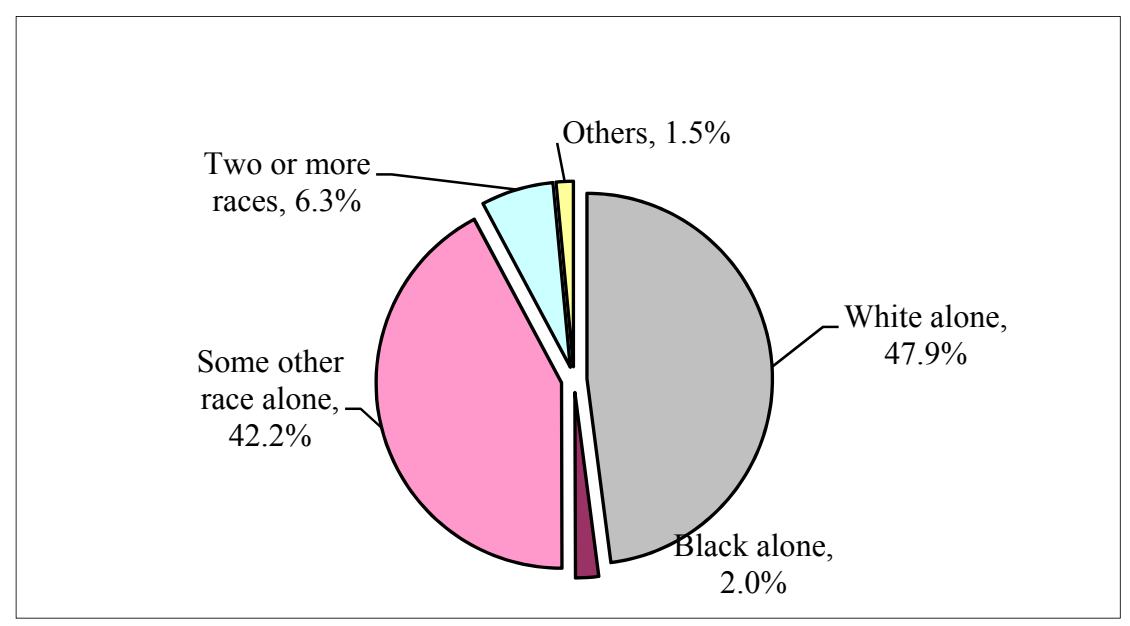

Figure 1. Latino population by race: 2010

Source: U.S. Census Bureau, Census 2010 SF1

The Census results have shown resistance among Latinos to the standard racial categories. Basically, the concept of race does not fully account for the mixed heritage some Latinos inherited with a strong indigenous influence. In other words, while there are clearly white Latinos and black Latinos, many more come from racially mixed backgrounds, with white, black and American Indian or other indigenous strains. In many ways, most of them are not purely black or white.

However, Latinos in the United States have been encouraged to fit into a bi-racial classification-oriented society (Oboler 1995). In various ways, many Latinos have unique experiences of being classified by others as white or black, depending on the context. In other words, although black Latinos share a culture and language with white Latinos, the race consciousness of America forces them to adopt an identity - as black Americans - that may not really be their own. Nonetheless, being black extensively matters to Latinos in the United States. Thus, despite the small portion of black Latinos within the Latino community, analysis of this small group can highlight how race is operating in the real world, combined with being of Latino origin.

Table 1 demonstrates racial compositions of selected Latino origin groups. Cubans are far more likely to choose "white alone" as their race than other Latino groups. The selection process influencing Cuban migration in the United States may explain the white race dominance phenomenon among Cuban-Americans. Panamanians have the highest percentage of blacks among Latino origin groups. The growing numbers of Dominicans, who are expected to eventually surpass Puerto Ricans as New York City's biggest Latino group, are not predominantly black on the basis of their self-identification, although others may generally see them as black. Rather, Dominicans have the highest rate of respondents who chose "some other race alone" among Latino subgroups. Dominicans have the lowest percentage of people who classified themselves as white among all the groups compared. 
Table 1. Selected Latino origin groups by race: 2010

\begin{tabular}{|c|c|c|c|c|c|c|}
\hline & $\begin{array}{l}\text { White } \\
\text { alone }\end{array}$ & $\begin{array}{l}\text { Black or } \\
\text { African } \\
\text { American } \\
\text { alone }\end{array}$ & $\begin{array}{l}\text { American } \\
\text { Indian, } \\
\text { Alaska } \\
\text { Native, } \\
\text { Asian, } \\
\text { Native } \\
\text { Hawaiian } \\
\text { alone }\end{array}$ & $\begin{array}{l}\text { Some } \\
\text { other } \\
\text { race } \\
\text { alone }\end{array}$ & $\begin{array}{l}\text { Two or } \\
\text { more } \\
\text { races }\end{array}$ & Total \\
\hline Mexican & $47.4 \%$ & $0.8 \%$ & $1.6 \%$ & $45.2 \%$ & $5.0 \%$ & $20,640,711$ \\
\hline Puerto Rican & $47.3 \%$ & $6.5 \%$ & $1.5 \%$ & $37.3 \%$ & $7.4 \%$ & $3,406,178$ \\
\hline Cuban & $84.4 \%$ & $3.8 \%$ & $0.8 \%$ & $7.2 \%$ & $3.8 \%$ & $1,241,685$ \\
\hline Dominican & $22.6 \%$ & $9.2 \%$ & $1.2 \%$ & $58.0 \%$ & $9.0 \%$ & 764,945 \\
\hline Salvadoran & $35.4 \%$ & $0.8 \%$ & $0.8 \%$ & $56.5 \%$ & $6.5 \%$ & 655,165 \\
\hline Colombian & $63.1 \%$ & $1.3 \%$ & $0.6 \%$ & $27.9 \%$ & $7.1 \%$ & 470,684 \\
\hline Guatemalan & $37.5 \%$ & $1.1 \%$ & $2.2 \%$ & $51.8 \%$ & $7.4 \%$ & 372,487 \\
\hline Ecuadorian & $48.8 \%$ & $0.8 \%$ & $1.1 \%$ & $41.6 \%$ & $7.7 \%$ & 260,559 \\
\hline Peruvian & $48.9 \%$ & $0.7 \%$ & $2.0 \%$ & $39.8 \%$ & $8.6 \%$ & 233,926 \\
\hline Honduran & $42.2 \%$ & $5.3 \%$ & $1.1 \%$ & $43.5 \%$ & $7.9 \%$ & 217,569 \\
\hline Nicaraguan & $55.5 \%$ & $1.6 \%$ & $0.8 \%$ & $34.4 \%$ & $7.7 \%$ & 177,684 \\
\hline Argentinean & $83.3 \%$ & $0.2 \%$ & $0.4 \%$ & $11.2 \%$ & $4.9 \%$ & 100,864 \\
\hline Panamanian & $28.3 \%$ & $30.1 \%$ & $1.2 \%$ & $27.1 \%$ & $13.3 \%$ & 91,723 \\
\hline Venezuelan & $69.4 \%$ & $2.1 \%$ & $0.6 \%$ & $20.8 \%$ & $7.1 \%$ & 91,507 \\
\hline Chilean & $71.2 \%$ & $0.3 \%$ & $0.6 \%$ & $20.6 \%$ & $7.3 \%$ & 68,849 \\
\hline Costa Rican & $59.8 \%$ & $5.5 \%$ & $0.7 \%$ & $25.8 \%$ & $8.2 \%$ & 68,588 \\
\hline Bolivian & $57.7 \%$ & $0.3 \%$ & $1.6 \%$ & $32.0 \%$ & $8.4 \%$ & 42,068 \\
\hline Uruguayan & $82.2 \%$ & $0.4 \%$ & $0.2 \%$ & $12.1 \%$ & $5.1 \%$ & 18,804 \\
\hline Paraguayan & $64.2 \%$ & $0.5 \%$ & $1.7 \%$ & $25.8 \%$ & $7.8 \%$ & 8,769 \\
\hline
\end{tabular}

Source: U.S. Census Bureau, Census 2010 SF1

Table 2 shows each Latino subgroup's share of all black Latinos. 31.3 percent of all black Latinos are Puerto Ricans while Mexicans constitute 22.6 percent. Dominicans are the third largest black Latino group. More Dominicans self-identified as black than Panamanians, although percentage-wise, a much higher proportion of Panamanians than Dominicans (30.1 percent versus 9.2 percent) considered themselves black. This is a very interesting finding, given that the Latino community considers Panamanians to be one of the dominant black Latino groups.

Table 3 shows the distribution of the 0.71 million black Latinos by state and metropolitan area, respectively. The proportion is much higher in New York State, which has a large concentration of Latinos from Caribbean countries with a legacy of African slavery. Of those Latinos in the United States who identified as black, 28.4 percent-around 200,000 - lived in New York State. California made up 11.5 percent of black Latinos while 10.0 percent of black Latinos lived in Florida. New York MSA contained the biggest proportion of all black Latinos (32.6 percent), followed by Los Angeles MSA and Miami MSA where 6.3 percent and 5.4 percent of black Latinos resided. Black Latinos reflect a larger pattern of immigrant growth in major metropolitan areas in the US. In both local community and national surveys of the population, persons of African descent who originate from the Caribbean region are, for the most part, designated as black Americans. 
Table 2. Black Latinos by national origin

\begin{tabular}{|c|c|c|}
\hline & Number & Share \\
\hline Total Black Latinos & 710,353 & $100.0 \%$ \\
\hline Puerto Rican & 222,148 & $31.3 \%$ \\
\hline Mexican & 160,218 & $22.6 \%$ \\
\hline Dominican & 70,216 & $9.9 \%$ \\
\hline Cuban & 47,671 & $6.7 \%$ \\
\hline Panamanian & 27,639 & $3.9 \%$ \\
\hline Honduran & 11,493 & $1.6 \%$ \\
\hline Colombian & 6,257 & $0.9 \%$ \\
\hline Salvadoran & 5,433 & $0.8 \%$ \\
\hline Guatemalan & 4,232 & $0.6 \%$ \\
\hline Costa Rican & 3,804 & $0.5 \%$ \\
\hline Nicaraguan & 2,912 & $0.4 \%$ \\
\hline Ecuadorian & 2,168 & $0.3 \%$ \\
\hline Venezuelan & 1,919 & $0.3 \%$ \\
\hline Peruvian & 1,689 & $0.2 \%$ \\
\hline All Other Latinos & 142,554 & $20.1 \%$ \\
\hline
\end{tabular}

Source: 2010 SF1 from Advanced Query System

As noted by several authors (Model 1991; Rodriguez 2000; Zavodny 2003), race status has been of overriding importance in American society and, as a consequence, the issue of racial differences within the Latino group has been largely ignored. More importantly, the failure to examine this source of intra-group variability potentially obscures important differences associated with ethnic and national heritage and life circumstances. Specifically, the distinctive histories and life experiences of blacks of Latino descent are likely to have important influences on shaping both the overall patterns and the correlates of economic well-being.

Table 3. Black Latino concentration by selected states and MSAs: 2010

\begin{tabular}{|c|c|c|c|}
\hline \multicolumn{2}{|c|}{ State } & \multicolumn{2}{|l|}{ MSA } \\
\hline New York & $28.4 \%$ & New York & $32.6 \%$ \\
\hline California & $11.5 \%$ & Los Angeles & $6.3 \%$ \\
\hline Florida & $10.0 \%$ & Miami & $5.4 \%$ \\
\hline New Jersey & $6.4 \%$ & Philadelphia & $3.4 \%$ \\
\hline Texas & $5.7 \%$ & Boston & $3.1 \%$ \\
\hline Illinois & $2.9 \%$ & Washington-Baltimore & $2.8 \%$ \\
\hline Arizona & $1.3 \%$ & Chicago & $2.8 \%$ \\
\hline Other states & $33.8 \%$ & Other MSAs and non-MSAs & $43.6 \%$ \\
\hline
\end{tabular}

Source: 2010 SF1 from Advanced Query System

Are different Latino subgroup residents more likely to self-identify their race in different regions? Mexican, Puerto Rican, Cuban, and other Latino residents in the South are more likely to self-identify "white alone" as their race than counterparts in other divisions (table not shown). However, the reason for this white race dominance in the South may vary across Latino subgroups, depending upon what impact migration or settlement patterns of each subgroup 
have had on its own racial identification. For example, black Cubans are more likely to settle down in the Northeast than in the South where white Cubans are highly concentrated. John Logan (2003) also found that metropolitan regions with large non-Latino white populations tended to have a larger share of white Latinos and those with larger non-Latino black population tended to have more black Latinos.

\section{Linking Low Economic Performance with Other Background Variables}

The low economic profile of black Latinos can be explained by variation of other background variables such as demographic, family structure, educational attainment, language, and occupation. For example, families maintained by women with no spouse present have higher poverty rates and lower incomes than married-couple families with spouse present. Reflecting this finding, individuals in female-maintained families were much more likely to participate in assistance programs. For people age 25 and over, lower educational attainment was associated with high poverty rate and greater welfare program participation rate. People without jobs--unemployed or out of the labor force--were much more likely to be poorer than were either full-time workers or part-time workers.

\subsection{Age Structure}

The black Latino population is now considerably younger on average than other Latino groups. The national percentage of persons under age 18 is 26 percent, age 18 to 64 - considered the economically productive group-is 62 percent, and age 65 and over is 12 percent. Table 4 provides a portrait of the age structure of race and Latino origin groups in the United States. Black Latinos are the youngest group among all compared race and Latino origin groups. The proportion of persons under age 18 is highest, while age 18 to 64 and age 65 and over have the lowest percentage. Black Latinos also have a lower proportion of people age 65 and older (5 percent), compared with 7 percent of Latino whites and 15 percent of non-Latino whites.

Table 4. Age structure and dependency rate by race and Latino origin

\begin{tabular}{lllll}
\hline & & & & $\begin{array}{l}\text { Dependency } \\
\text { Rate }\end{array}$ \\
\hline Latino & $34.8 \%$ & $18-64$ & 65 or over & 65.6 \\
\hline Latino White & $32.8 \%$ & $60.4 \%$ & $4.8 \%$ & $65 \%$ \\
\hline Latino Black & $37.6 \%$ & $60.4 \%$ & $6.8 \%$ & 65.6 \\
\hline Non-Latino & $24.3 \%$ & $57.3 \%$ & $5.1 \%$ & 74.5 \\
\hline $\begin{array}{l}\text { Non-Latino } \\
\text { White }\end{array}$ & $22.6 \%$ & $62.2 \%$ & $13.5 \%$ & 60.8 \\
\hline $\begin{array}{l}\text { Non-Latino } \\
\text { Black }\end{array}$ & $31.2 \%$ & $62.3 \%$ & $15.0 \%$ & 60.4 \\
\hline
\end{tabular}

Source: U.S. Census Bureau, Census 2010 Sample Data File

One frequently used measure is the ratio of economically active to economically inactive persons in a population. This ratio is called the dependency ratio and is defined as: population of children (below 18) plus population of the elderly ( 65 or over) divided by population between ages 18 and 64. As Table 4 shows, the black Latinos' dependency ratio (74) is much higher than those of other groups, meaning that black Latinos have the lowest percentage in the economically active age group, which may result in low economic performance.

\subsection{Educational Attainment}

Educational attainment is a good predictor of an individual's economic well-being. The educational levels of the United States population reached an all-time high, according to the 2010 Census. Of the 182.2 million people aged 25 and over on April 1, 2010, 80 percent had a high school diploma or more, and 24 percent had completed at least a bachelor's degree. Table 5 breaks down data on the educational attainment of people 25 years and over in the United States and demonstrates a large disparity in educational attainment between Latinos and non-Latinos. In 2010, the proportion of people aged 25 and over who had completed high school or more ranged from 86 percent for non-Latinos overall to 52 percent for Latinos overall. A large gap between the Latino population and the non-Latino 
population is also seen at other levels of education. For example, only 11 percent of all Latinos had a bachelor's degree or more while 26 percent of the non-Latino population reached this education level.

Large differences also existed among races at all levels of education. Non-Latino whites were most likely to report having completed higher levels of education while white Latinos were least likely to. Only 13 percent of white Latinos had a bachelor's degree or more while 27 percent of non-Latino whites reached this education level. In 2010, only 56 percent of white Latinos had completed high school or more while 85 percent of non-Latino whites were in a comparable position. In the same vein, white Latinos have the highest percentage of below high school attendees and high school drop outs.

On the other hand, black Latinos and non-Latino blacks fare better compared to Latinos overall and white Latinos. In 2010, the proportion of people aged 25 and over who had completed high school or more were 56 percent for white Latinos. The corresponding rates for black Latinos and non-Latino blacks were 63 percent and 72 percent, respectively. Black Latinos have a slightly lower percentage of people with a college degree and graduate degree than non-Latino blacks, but they have the same percentage as white Latinos. Given that black Latinos have little edge over white Latinos in terms of educational attainment, black Latinos should have better economic well-being than white Latinos. As already shown, however, our analyses results do not support this assumption. Therefore, our suspicion is that race may be associated with the low economic performance of black Latinos (Davis 2016).

Table 5. Educatgion attainment by race and ethnicity (age 25 or over): 2010

\begin{tabular}{|c|c|c|c|c|c|c|c|}
\hline & $\begin{array}{l}\text { Below } \\
9 \text { th } \\
\text { grade }\end{array}$ & $\begin{array}{l}\text { High } \\
\text { school, } \\
\text { no } \\
\text { diploma }\end{array}$ & $\begin{array}{l}\text { High } \\
\text { school } \\
\text { graduate }\end{array}$ & $\begin{array}{l}\text { Some } \\
\text { college, } \\
\text { no } \\
\text { degree }\end{array}$ & Associate & Bachelor & Graduate \\
\hline Latino & $27.8 \%$ & $19.7 \%$ & $22.1 \%$ & $15.6 \%$ & $4.3 \%$ & $6.7 \%$ & $3.8 \%$ \\
\hline \multicolumn{8}{|l|}{ Latino } \\
\hline White & $24.7 \%$ & $18.6 \%$ & $22.2 \%$ & $16.4 \%$ & $4.6 \%$ & $8.1 \%$ & $5.1 \%$ \\
\hline \multicolumn{8}{|l|}{ Latino } \\
\hline Black & $16.4 \%$ & $21.4 \%$ & $25.2 \%$ & $18.9 \%$ & $5.5 \%$ & $8.1 \%$ & $4.5 \%$ \\
\hline Non-Latino & $5.3 \%$ & $11.2 \%$ & $29.4 \%$ & $21.7 \%$ & $6.5 \%$ & $16.5 \%$ & $9.4 \%$ \\
\hline \multicolumn{8}{|l|}{ Non-Latino } \\
\hline White & $4.6 \%$ & $10.0 \%$ & $30.0 \%$ & $21.9 \%$ & $6.6 \%$ & $17.2 \%$ & $9.8 \%$ \\
\hline \multicolumn{8}{|l|}{ Non-Latino } \\
\hline Black & $7.8 \%$ & $19.8 \%$ & $29.8 \%$ & $22.5 \%$ & $5.8 \%$ & $9.5 \%$ & $4.8 \%$ \\
\hline
\end{tabular}

Source: U.S. Census Bureau, Census 2010 Sample Data File

\subsection{Employment, Occupation, and Industry}

The lower income facing the black Latino population in 2010, compared to other racial and ethnic groups in the United States, can be explained in large part by the labor market challenges encountered by black Latinos. Black Latinos and non-Latino blacks share a similar profile in the labor market. Table 6 displays the proportion of the labor force that was unemployed in 2010 for various ethnic/racial groups in the United States. As the data show, the unemployment rate of black Latinos was more than twice the overall non-Latinos' unemployment rate of 5.3 percent and was nearly triple the 4 percent of non-Latino whites who were unemployed. The unemployment rate of black Latinos was also 50 percent higher than the 8 percent of white Latinos. Of non-Latino blacks, 11 percent were unemployed. Higher unemployment rates are significantly linked to educational attainment. The lower the educational attainment, the higher the likelihood of unemployment. However, black Latinos have a higher unemployment rate than white Latinos, despite having a relatively higher level of education. Thus again being black, combined with Latino origin, may produce a negative interaction effect on employment status. 
Table 6 also presents the U.S. employment part time rate in 2010, decomposed by race and Latino origin. Again, black Latinos and non-Latino blacks are similar. For instance, both of these groups worked slightly more part-time (Note 4) during the year compared to white Latinos or non-Latino whites. Thus, the full time rates of black Latinos and non-Latino whites were approximately 73 percent and 75 percent, quite below those of non-Latino whites and even of white Latinos. Similarly, black Latinos and non-Latino blacks had the lowest representation among those who classified themselves as "Self-Employed."

Table 6 highlights the occupations of American workers by race and Latino origin. As Table 6 shows, 19 percent of the black Latinos' labor force was in managerial, professional and technical occupations, compared to 34 percent for the non-Latino white labor force. Non-Latino whites were more often in management, professional, and related occupations than other racial groups. At the least-detailed summary level (six occupational groups) for employed civilian men and women 16 and older, management, professional, and related occupations paid the most (Fronczek and Johnson 2003). Approximately one-fifth (22 percent) of Latinos were employed in "Production, transportation, and material moving occupations" which is the second highest paying occupational group for men. In contrast, only 14 percent of non-Latino whites were in this group. Black Latinos had a relatively low representation of persons working in these occupations in 2010. Black Latinos and non-Latino blacks have the higher representation in occupations involving "Service." Again race seems to weigh more in determining occupation when race is combined with Latino ethnicity. The less-skilled occupations obtained by the black Latino workers explain to a large extent their low economic performance.

Table 6 . Employment status, occupation and industry by race and ethnicity: 2010

\begin{tabular}{|c|c|c|c|c|c|c|c|}
\hline & \multicolumn{3}{|c|}{ Employment Status } & \multicolumn{4}{|c|}{ Occupation and Industry } \\
\hline & Unemployed & $\begin{array}{l}\text { Part time } \\
\text { workers } \\
\text { in } 2009\end{array}$ & $\begin{array}{l}\text { Self } \\
\text {-employed }\end{array}$ & $\begin{array}{l}\text { Management } \\
\text { and } \\
\text { professional }\end{array}$ & $\begin{array}{l}\text { Production } \\
\text { and } \\
\text { transportation }\end{array}$ & Service & Manu-facture \\
\hline Latino & $9.2 \%$ & $25.1 \%$ & $6.6 \%$ & $15.8 \%$ & $21.6 \%$ & $22.3 \%$ & $15.7 \%$ \\
\hline $\begin{array}{l}\text { Latino } \\
\text { white }\end{array}$ & $8.4 \%$ & $23.9 \%$ & $7.3 \%$ & $18.9 \%$ & $19.8 \%$ & $21.5 \%$ & $14.6 \%$ \\
\hline Latino & & & & & & & \\
\hline Black & $12.3 \%$ & $27.3 \%$ & $5.3 \%$ & $18.9 \%$ & $18.2 \%$ & $24.1 \%$ & $12.2 \%$ \\
\hline Non-Latino & $5.3 \%$ & $20.4 \%$ & $9.7 \%$ & $32.5 \%$ & $14.2 \%$ & $15.5 \%$ & $13.5 \%$ \\
\hline $\begin{array}{l}\text { Non-Latino } \\
\text { white }\end{array}$ & $4.3 \%$ & $19.4 \%$ & $10.6 \%$ & $34.0 \%$ & $13.5 \%$ & $14.1 \%$ & $13.5 \%$ \\
\hline $\begin{array}{l}\text { Non-Latino } \\
\text { Black }\end{array}$ & $11.4 \%$ & $25.5 \%$ & $4.4 \%$ & $21.5 \%$ & $19.0 \%$ & $23.2 \%$ & $12.8 \%$ \\
\hline
\end{tabular}

*Universe: Unemployment: age 16 or over and in the labor force

Part time workers ( 1 to 39 weeks): age 16 or over and worked in 2009

Class of worker: age 16 or over and worked in the last 5 years

Occupation and Industry: age 16 or over and in labor force

Source: U.S. Census Bureau, Census 2000 Sample Data File

The industrial composition of the labor force reflects the sector of employment of persons in the labor force in 2010 . From a statistical point of view, there is not much difference among the groups compared concerning the category "Manufacturing". Yet, black Latinos are slightly below the rest of the groups, and non-Latino whites and white Latinos are slightly above non-Latino blacks and black Latinos. 
The wide gap in occupation earnings between black Latino (or non-Latino black) workers and the other workers helps explain the economic disparity noted earlier. Combined with the higher unemployment rates of black Latinos, these two forces explain to a large extent the comparatively high poverty rate of black Latinos in the United States.

\subsection{Nativity, Language, Marriage Stability, and Migration Status}

Table 7 shows differentials by race and Latino origin in terms of nativity, language marriage stability, and migration status. First, in terms of nativity and English fluency, black Latinos are not akin to those of non-Latino blacks but rather they are more similar to white Latinos and Latinos overall. However, black Latinos are in a more favorable position than white Latinos and Latinos overall. For example, black Latinos have a noticeably lower percentage of immigrants than white Latinos and Latinos overall. Thus, as compared to white Latinos and Latinos overall, black Latinos have a lower percentage of people who speak "language other than English at home." In the same vein, black Latinos have a higher percentage of people who speak "English well and Very Well" and a lower percentage of people who have difficulty with English among Latino groups, mainly due to higher proportion of U.S.-born people. Black Latinos' high level of English fluency should have had a positive effect on their economic performance, relative to white Latinos and Latinos overall, but apparently the reality is not working in that direction.

Table 7. Nativity, language use, English-speaking ability, marital status, and geographical mobility by race and Latino origin

\begin{tabular}{|c|c|c|c|c|c|c|c|}
\hline & Foreign-born & $\begin{array}{l}\text { Speak } \\
\text { language } \\
\text { other than } \\
\text { English at } \\
\text { home }^{1}\end{array}$ & $\begin{array}{l}\text { Speak } \\
\text { English } \\
\text { Not Well } \\
\text { and Not at } \\
\text { all }^{2}\end{array}$ & $\begin{array}{l}\text { Households } \\
\text { with Related } \\
\text { Children } \\
\text { headed by } \\
\text { Female }\end{array}$ & $\begin{array}{l}\text { Now } \\
\text { married, } \\
\text { spouse } \\
\text { present }^{3}\end{array}$ & Movers $^{1}$ & $\begin{array}{l}\text { Different } \\
\text { House - } \\
\text { Not in US } \\
\text { State }^{1}\end{array}$ \\
\hline Latino & $40.2 \%$ & $70.4 \%$ & $30.1 \%$ & $31.1 \%$ & $67.5 \%$ & $55.5 \%$ & $9.6 \%$ \\
\hline Latino White & $38.8 \%$ & $69.3 \%$ & $29.5 \%$ & $28.9 \%$ & $68.2 \%$ & $53.0 \%$ & $9.6 \%$ \\
\hline Latino Black & $29.1 \%$ & $55.3 \%$ & $24.5 \%$ & $56.5 \%$ & $53.5 \%$ & $55.7 \%$ & $8.1 \%$ \\
\hline Non- Latino & $6.9 \%$ & $9.0 \%$ & $15.9 \%$ & $30.1 \%$ & $70.4 \%$ & $44.6 \%$ & $1.9 \%$ \\
\hline \multicolumn{8}{|l|}{ Non-Latino } \\
\hline White & $3.5 \%$ & $5.6 \%$ & $12.8 \%$ & $24.0 \%$ & $72.5 \%$ & $43.1 \%$ & $1.1 \%$ \\
\hline \multicolumn{8}{|l|}{ Non-Latino } \\
\hline Black & $5.7 \%$ & $5.5 \%$ & $13.1 \%$ & $59.4 \%$ & $51.5 \%$ & $48.6 \%$ & $2.2 \%$ \\
\hline
\end{tabular}

1. Universe: age 5 and over

2. Universe: who speak language other than English

3. Age 15 and over who now married

Source: U.S. Census Bureau, Census 2010 Sample Data File

The questions dealing with marriage stability indicate that black Latinos more closely mirror those of non-Latino blacks than of white Latinos and Latinos overall. "Married, spouse present" applies to husbands and wives if both were living in the same household. (Note 5) Nearly 1 out of every 2 married black Latinos and non-Latino blacks has their spouse absent from their house for some reason or has been "widowed," "divorced," or "separated," but has not remarried. Similarly, black Latinos and non-Latino blacks have a much higher percentage of households with related children headed by women than Latinos overall, white Latinos, and non-Latino whites. This implies that marital discord has been widespread among black Latinos and non-Latino blacks. Marital instability is a major concern because it has a significant impact on the economic well-being of black Latinos and especially on their children's living conditions. For example, the poverty rate for children growing up in a married-couple family is one-fourth the rate of those growing up in single-parent families (O'Hare 2004). Thus, the structure of families and marital stability is another factor that carries significant implications for the high poverty rate and the low income of black Latinos. 
The last two rows in Table 7 highlight the geographical mobility of people 5 and older; more specifically, it focuses on "movers"- that is, people who lived in a different home in 2010 than they did in 2005 (Berkner and Faber 2003). Our analysis shows that moving rates and types of moves differed by racial and ethnic characteristics. Less than half of non-Latinos overall, non-Latino whites, and non-Latino blacks moved during the 2005 to 2010 period, while black Latinos and white Latinos had higher moving rates. The 5-year moving rate was approximately 57 percent for black Latinos, which was much higher than the national moving rate of 46 percent. However, black Latinos were less likely to move than white Latinos. Non-Latino whites were the least mobile racial or ethnic group. Lastly, black Latinos and white Latinos were much more likely than any of the other groups to have moved from abroad, mostly due to the large proportion of their population that is foreign born.

These findings reflect that residential settlement is less stable among black Latino groups. Further, it may suggest that being black could have some effect on migration patterns. Black Latinos' high moving rates seem related to their racial identification. For example, while white Cuban-Americans are concentrated in the state of Florida and New Jersey, black Cuban-Americans seem to be moving in a different direction. New York State is home to approximately 35 percent of all black Cuban-Americans, which is by far the largest single concentration of black Cuban-Americans in the United States (Dixon 1988).

\section{Black Latinos: Economic Profile}

\subsection{Poverty}

Poverty rate data offer an important way to evaluate race and Latino origin groups' economic well-being. Although poor people in the United States are too diverse to be characterized along any one dimension, the incidence of poverty varied considerably across race and Latino origin groups. Table 8 illustrates that 28 percent of black Latinos lived below the poverty line, markedly surpassing the overall national rate of 12 percent and non-Latinos' overall poverty rate of 11 percent. Black Latinos in general were also more apt to encounter poverty than the comparable total Latino group and white Latinos. Black Latinos are almost four times more likely to live in poverty than non-Latino whites. However, black Latinos' poverty rate was only 3 percent higher than non-Latino blacks. Thus Table 8 clearly illustrates that being black, combined with being of Latino origin, has a significant impact on determining poverty rate.

\subsection{Income and Housing}

Table 8 examines the 2009 individual earnings for persons 16-years-old or over and household income of black Latinos relative to white Latinos and non-Latinos. The results indicate that, at least in 2009 the facts do not justify the opinion that black Latinos had higher income than non-Latino blacks in terms of both individual earnings and total household income. In addition, black Latinos fared worse compared to white Latinos. Black Latinos experienced vast individual earnings and household income disparities relative to non-Latino whites.

Table 8 highlights housing in 2010. Housing tenure identifies a basic feature of the housing inventory, whether a unit is owner or renter occupied. Owning one's home has long been considered a part of the "American Dream." The 2010 Census showed that about 2 out of 3 householders ( 66 percent) attained this goal. The remaining 34 percent of occupied units were rented or occupied without payment or cash rent.

According to Table 8, white-Latinos have a higher rate of homeownership than any other Latino subgroup. Yet, their number is significantly lower compared to non-Latino whites or even non-Latinos overall. The explanation behind this is that Latinos, as a whole, already have lower incomes when compared to non-Latino whites. Race, however, seems to play a role since white Latinos have a higher rate of homeownership than black Latinos. Black Latinos also have lower income and owning a home is directly linked to income.

Black Latinos were more likely to rent their homes and to carry a heavy rent burden than other groups. In terms of renting or homeownership, 71 percent of black Latino households rented and just 29 percent owned their homes, compared with 53 percent renters and 47 percent owners for non-Latino blacks. Homeownership rate of black Latino households was far below the national average of 68 percent. The disparity in homeownership rate between black Latinos and non-Latino blacks is unusually large, considering that black Latinos are close to non-Latino blacks in most economic indicators. These findings demonstrate that being black along with being Latino has a negative interaction effect on gaining access to homeownership.

The low homeownership rate of black Latinos could most reasonably be explained by the fact that many black Latinos live in New York where the percentage of renter-occupied units is highest among large cities in the United States. It is also plausible that black Latinos, like non-Latino blacks, face discrimination in a racially restrictive housing market (Adelman and others 2001). 
Table 8 . Economic profile by race and ethnicity

\begin{tabular}{|c|c|c|c|c|c|c|}
\hline & & \multicolumn{3}{|l|}{ Individual (16 } & \multirow{2}{*}{$\begin{array}{l}\text { Received } \\
\text { Public }\end{array}$} & \multirow{2}{*}{$\begin{array}{l}\text { Received } \\
\text { Supplemental }\end{array}$} \\
\hline & & or over) & Household & & & \\
\hline & Individuals & earning & income & & Assistance & Security \\
\hline & below & $\$ 35,000$ or & $\$ 50,000$ or & & Income in & Income in \\
\hline & & & & Homeownership & & \\
\hline Latino & $22.6 \%$ & $17.4 \%$ & $34.2 \%$ & $46.4 \%$ & $2.2 \%$ & $1.8 \%$ \\
\hline Latino white & $10.9 \%$ & $20.2 \%$ & $36.9 \%$ & $51.7 \%$ & $1.9 \%$ & $2.0 \%$ \\
\hline Latino black & $28.1 \%$ & $19.0 \%$ & $29.7 \%$ & $29.2 \%$ & $3.7 \%$ & $3.1 \%$ \\
\hline Non-Latino & $24.8 \%$ & $33.8 \%$ & $53.4 \%$ & $68.6 \%$ & $1.4 \%$ & $2.0 \%$ \\
\hline Non-Latino White & $20.8 \%$ & $35.5 \%$ & $56.5 \%$ & $72.9 \%$ & $1.0 \%$ & $1.7 \%$ \\
\hline Non-Latino Black & $8.1 \%$ & $22.9 \%$ & $34.0 \%$ & $47.3 \%$ & $3.3 \%$ & $3.5 \%$ \\
\hline
\end{tabular}

Source: 2010 SF3 from Advanced Query System

\subsection{Welfare Program Participation}

A small proportion of people living in the United States receive supplemental security income (SSI) and cash public assistance. Since 1974, SSI has provided economic assistance to people with low incomes and resources and who are disabled or aged (Jones 2003). Despite providing payments to only a small portion of the population, SSI and cash public assistance are extremely important to those covered by these programs because they are among the poorest individuals in the nation and most in need of assistance.

Table 8 provides initial insight into how race and Latino origin corresponds with welfare programs such as supplemental security income (SSI) and public assistance. (Note 6)

Variation in poverty rates among the racial and Latino-origin groups can, in part, explain differences in welfare program participation. Poverty and participation in welfare programs may be closely related. Thus, we expect that the participation rate of Latinos in welfare programs is much higher than the rate of non-Latinos.

However, Latinos' participation rate in welfare program is almost equivalent to that of non-Latinos as a whole. Yet, the likelihood of receiving SSI and cash public assistance still differs among racial groups. According to Table 8, black Latinos and non-Latino blacks share a similar profile in terms of public assistance recipient rate and SSI recipient rate. They have higher representation among public recipients and supplemental security income rates compared to non-Latino whites and white Latinos. In 2009, the participation rate in the primary public assistance program for black Latinos (3.7 percent) was almost two times that of Latino whites (1.9 percent) and nearly four times that of non-Latino whites (1.0 percent). The corresponding figure was 3.3 percent for non-Latino blacks.

Table 8 also provides a brief look at SSI recipients by race and Latino origin. Individuals of Latino origin were less likely to receive assistance than non-Latinos, in part due to young age structure. Yet, the likelihood of receiving public assistance still differs between black and white groups, regardless of their Latino origin. SSI provided income assistance to 3.1 percent of black Latinos and 3.5 percent of non-Latino blacks. In comparison, 2.0 percent of white Latinos and 1.7 percent of non-Latino whites were covered by payments from the SSI program.

\section{Discussion}

This study tackles the controversial subject of race within the multinational and multiracial Latino context. How does race influence the economic characteristics of Latinos? Results of this study demonstrate that white Latinos are more successful than black Latinos in terms of general economic performance measures, presumably by virtue of their non-black status. In addition, our analyses show that black Latinos have more in common with non-Latino blacks than with Latinos overall and white Latinos. (Note 7) In all of our economic indicators, non-Latino whites excel beyond all other racial and ethnic groups analyzed.

Our analyses also show that black Latinos and non-Latino blacks share similar social, family, and demographic backgrounds, which may have a negative impact on their economic performance. Nevertheless, it should be recognized that some background indicators of black Latinos, such as a relatively high educational level, high percentage of native-borns and consequently high level of English fluency, relative to white Latinos, have not 
worked in a positive direction as expected. This enables us to assume that being black, regardless of Latino origin, has some impact on economic performance (Davis 2016). Otherwise, other negative indicators might nullify the influence of these positive forces. Furthermore, other factors such as nationality and nativity could be involved. In particular, nationality could be more important to explaining variation in Latinos' economic performance. Latinos might separate themselves more strongly by nationality rather than by skin color. Thus, further analysis is necessary to identify how diverse socio, family, and demographic variables are operating in determining low performance of black Latinos.

Nonetheless, we believe that race is an independent factor affecting low economic performance of black Latinos. Race matters. It is not deniable that race has played a role in determining black Latinos' low economic performance. Our further analyses (Note 8) find that black and white disparities vary among Latino origin groups. In terms of poverty rate and median household income, black Latinos have significantly disadvantaged profiles compared to their white counterparts virtually within every Latino national group, although Dominicans have less meaningful disparity between black and white. This finding illustrates that a race is independently associated with economic performance even within the same ethnic group (Zavodny 2003).

In an attempt to be more sophisticated in understanding racial issues in the United States, our research simply raises crucial issues about the rapidly growing Latino population and contributes to understanding better the diversity both within the Latino community and in the nation as a whole by highlighting the distinctiveness of each Latino origin and racial group (Oboler 1995). Our findings indicate the importance of race combined with Latino ethnicity. Race seems to weigh more when the two factors are combined.

\section{Limitations of the Study}

Our foregoing discussion has focused on the net racial effects, but we could not test whether racial differences are statistically explained by other socioeconomic characteristics or human capital variables. Aggregate datasets did not allow us to control for other variables. Thus, their effects need to be investigated in further research. Our further analysis will identify how diverse socio, family, and demographic variables are operating in determining low performance of black Latinos.

\section{References}

Adelman, Robert M., Hui-shien Tsao, Stewart E. Tolnay, \& Kyle D. Crowder. (2001). Neighborhood Disadvantage among Racial and Ethnic Groups: Residential Location in 1970 and 1980. The Sociological Quarterly, 42(4), 603-632. http://dx.doi.org/10.1111/j.1533-8525.2001.tb01782.x

Beckner, Bonny, \& Carol S. Faber. (2003). Geographical Mobility: 1995 to 2000, Census 2000 Brief, September 2003. U.S. Census Bureau.

Davis, Tomeka M. (2016). Parental race as symbolic and social capital: teacher evaluations of part-white biracial and monoracial minority students. Race Ethnicity and Education, 19(2), 339-367. http://dx.doi.org/10.1080/13613324.2015.1046827

Dixon, Heriberto. (1988). The Cuban-American Counterpoint: Black Cubans in the United States. Dialectical Anthropology, 13, 227-239.

Fronczek, Peter, \& Patricia Johnson. (2003). Occupations: 2000, Census 2000 Brief, August 2003. U.S. Census Bureau.

Gómez, Christina. (2000). The Continual Significance of Skin Color; An Exploratory Study of Latinos in the Northeast. Hispanic Journal of Behavioral Sciences, 22(1), 94-103. http://dx.doi.org/10.1177/0739986300221005

Jones, Arthur. (2003). Supplemental Security Income and Its Noninstitutional Recipients: July 1997 and 1999. Current Population Reports, August 2003. U.S. Census Bureau.

Kreider, Rose. M., \& Tavia Simmons. (2003). Marital Status: 2000. Current Population Reports, October 2003,U.S.Census Bureau.

Lester, Gordon H., \& Jan Tin. (2004). Dynamics of Economic Well-Being: Program Participation, 1996 to 1999 Who Gets Assistance?. Current Population Reports, January 2004, U.S. Census Bureau.

Logan, John R. (2003). How Race Counts for Hispanic Americans. Albany: Lewis Mumford Center, University of Albany, July 2003. Retrieved from http://mumford1.dyndns.org/cen2000/BlackLatinoReport/BlackLatinoReport.doc 
Model, Suzanne. (1991). Caribbean Immigrants: A Black Success Story?. International Migration Review, 25(2), 248-276. http://dx.doi.org/10.2307/2546288

Oboler, Suzanne. (1995). Ethnic Labels, Latino Lives: Identity and the Politics of Representation. St. Paul: University of Minnesota Press.

O'Hare, William P., \& Kenneth M. Johnson. (2004). Child Poverty in Rural America. Report on America, 4(1), March 2004. Washington DC: Population Reference Bureau.

Rodriguez, Clara E. (2000). Changing Race: Latinos, the Census, and the History of Ethnicity in the United States. New York: New York University Press.

Scherer, Michael. (2003, Jan-Feb). Census Confusion: Have Latinos Surpassed Blacks as the Largest Minority in America? It depends who Reports the Story. Columbia Journalism Review.

Zavella, Patricia. (1997). Reflecting on Diversity among Chicanas. In Mary Romero, Pierrete Hondagneu-Sotelo, \& Vilma Ortiz (Eds.), Challenging Fronteras: Structuring Latino and Latino Lives in the United States, An Anothology of Readings (pp. 187-194). New York: Routledge.

Zavodny, Madeline. (2003). Race, wages, and assimilation among Cuban immigrants. Population Research and Policy Review, 22, 201-219. http://dx.doi.org/10.1023/A:1026025024501

\section{Notes}

Note 1. John Logan's analysis (2003) tells why Latinos are sometimes classified as blacks. John Logan, from the Lewis Munford Center, believes that black Latinos are blacks because they have one parent who is non-Latino black. Logan is correct when we look at black Mexicans and perhaps black Puerto Ricans. However, this is not the case for Dominican people. Black Dominicans are blacks because they perceive themselves as such rather than because of having one parent who is non-Latino black.

Note 2. Our analysis includes only "white Latinos," "black Latinos," and "Latinos overall." Thus, "Asian Latinos," "American Indian Latinos," and so called "Hispanic Hispanics" (Logan 2003) who indicated "Hispanic or Latino," and "Other race alone" in the 2010 census were excluded.

Note 3. Depending on how blacks and Latinos are counted, we can say that blacks may outnumber Latinos. For example, if Latinos who consider themselves at least partly black are counted as blacks, assuming that race and ethnicity are comparable minority group categories, blacks still could be the larger minority group (Scherer 2003).

Note 4. Part-time workers are defined here as people who worked 1 to 39 weeks in 2009.

Note 5. This "Married, spouse absent" applies to husbands and wives who answered that they were "Now married" on the census form but no spouse could be found who could be linked to them in the editing stages. All people in group quarters housing who reported that they were "Now married" were subsequently assigned to the "Married, spouse absent" category in the recoding steps. The other categories in the universe of marriage stability measure are "Separated," "Divorced," and "Widowed." The "Never married" category was excluded from the universe of this measure. (see Kreider and Simmons 2003).

Note 6. Means-tested public-assistance programs are those that require income and/or assets of the individual or family to be below specified thresholds in order to qualify for benefits. These programs provide cash and non-cash assistance to eligible individuals and families (Lester and Tin 2004).

Note 7. One exception would be those from the West Indies. Writers have characterized Caribbean nationals, especially those from the English speaking West Indies, as more educated, more entrepreneurial, stronger in conjugal ties, higher in occupational status, and richer in earnings than native-born blacks. Yet, others argued that these characterizations were unaccompanied by either theoretical advances or analytical support(Model 1991).

Note 8. Results are not shown here in this paper. 